\title{
Microalgae: A Renewable Source for Wastewater Treatment and Feedstock Supply for Biofuel Generation
}

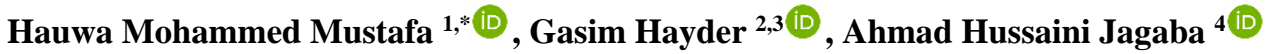 \\ 1 College of Graduate Studies, Universiti Tenaga Nasional (UNITEN), 43000 Kajang, Selangor Darul Ehsan, Malaysia \\ 2 Institute of Energy Infrastructure (IEI), Universiti Tenaga Nasional (UNITEN), 43000 Kajang, Selangor Darul Ehsan, \\ Malaysia \\ 3 Department of Civil Engineering, College of Engineering, Universiti Tenaga Nasional (UNITEN), 43000 Kajang, Selangor \\ Darul Ehsan, Malaysia \\ 4 Department of Civil and Environmental Engineering, Universiti Teknologi PETRONAS (UTP), Bandar Seri Iskandar, \\ Perak Darul Ridzuan, Malaysia \\ * Correspondence: hauwa.mustafa@uniten.edu.my;
}

Scopus Author ID 56239664100

Received: 27.05.2020; Revised: 14.06.2020; Accepted: 14.06.2020; Published: 17.06.2020

\begin{abstract}
The search and exploitation of renewable clean energy sources have become crucial, because of the developing day by day interest for clean water and energy affected by the improvement of the economy, population, industrialization, urbanization, insufficient energy, climate abnormalities, and environmental pollution. The major cause of emissions of harmful gases into the environment is due to the high utilization of petroleum derivatives. In this way, it is paramount to explore environmentally sustainable energy sources for feasible advancement, to satisfy these expanding energy demands and to secure the environment. To mitigate these global problems, academic, industrial, and governmental sectors have engaged in a lot of brainstorming and research to surmount these difficulties, which have brought a steady flow of new information in the area of cultivation of microalgae in innovative technologies including photobioreactors and high rate algal ponds. In this respect, biomass generation from aquatic plants in enriched aquatic environments like wastewater has received considerable. Therefore, this review article provides comprehensive information on recent accounts on applications of microalgae in wastewater treatment using different technologies and their potentials in feedstock generation for biofuels applications. However, in the course of this study, high rate algal ponds (HRAP) and photobioreactors were found to be a reliable system for the cultivation of microalgae and wastewater treatment. Hence, the two-step method of dewatering methods is found to be the most effective approach for microalgae cultivation for wastewater treatment and generation of algal-based feedstock, taking into account high yield potentials and economic factors such as cost of operation and energy required for large scale algal biomass processing for biofuel generations.
\end{abstract}

Keywords: wastewater treatment; high rate algal ponds; photobioreactors; biomass; flotation; centrifugation; magnetic separation.

(C) 2020 by the authors. This article is an open-access article distributed under the terms and conditions of the Creative Commons Attribution (CC BY) license (https://creativecommons.org/licenses/by/4.0/).

\section{Introduction}

The search and exploitation of renewable clean energy sources have become crucial, because of the developing day by day interest for clean water and energy affected by the improvement of the economy, population, industrialization, urbanization [1], insufficient energy, climate abnormalities and environmental pollution [2,3]. Presently, petroleum derivatives are the primary wellspring of energy; they are unsustainable and cannot be 
replenished within a short period. The major cause of emissions of harmful gases into the environment is due to the high utilization of petroleum derivatives. In this way, it is paramount to explore environmentally sustainable energy sources for available advancement, to satisfy these expanding energy demands and to secure the environment [1].

The combination of energy and recovery of water from domestic or industrial wastewater sources could be a possible solution to tackle these problems because the perception of wastewater has changed in the previous years, as it is no more considered as waste, but a wellspring of supplements ( $\mathrm{K}, \mathrm{N}$, and $\mathrm{P})$, water, and energy [4]. Waste is a raw material that can be converted into resourceful materials used in the production of new materials, energy transporter, or as supplements wellspring for land applications. Absolute waste production and disposal is a global challenge projected to rise consistently in every part of the world [5]. Annually, global waste production is estimated to reach up to billions of tonnes [5]. At the same time, about 1.8 billion people access water contaminated with feces, making them vulnerable to water-related diseases like dysentery, polio, cholera, and typhoid [6]. This has resulted in making the plight for effective waste treatment measures increasingly indispensable.

Biomass (feedstock) is viewed among the essential wellspring of energy in developing nations like Turkey and Malaysia. It keeps on being the perfect answer for environmental change and energy sustainability, particularly in its conventional structure [7], because it is a source of energy that has a bit of leeway over other renewable energy sources due to long storage time and can replenish annually from different sources. This review study discussed recent accounts on the simultaneous applications and potentials of microalgae in wastewater treatment and algal-based feedstock using high rate algal ponds and photobioreactors.

\section{Materials and Methods}

Microalgae are organisms that complete photosynthesis by utilizing carbon dioxide to produce profitable compounds as feedstock [8]. They comprised of large groups of autotrophic microorganism species [9], that can develop in different aquatic environments, like marine and freshwater, industrial wastewater [10], domestic wastewater [11], animal wastewater [12], in the presence of sufficient amount of carbon (inorganic or organic), nitrogen (nitrate, ammonium or urea), phosphorous and some trace elements. The overall market potentialities for algal-based products are expected to hit about 1143 million dollars by the year 2024 [13]. Meanwhile, viable market potentials for microalgae in phytoremediation of wastewater and biofuels are presently increasing day by day. Moreover, the high yield of Botryococcus braunii and Chlorella Vulgaris species of microalgae can be used to generate a large amount of liquid feedstock for biofuel production [14], and other synthetic substances or crude materials that are useful in cosmetics, pharmaceutical, and nutraceutical industries [15]. However, microalgae seem to be the main current sustainable approach to generate biofuels $[16,17]$. Microalgal biofuels are characterized by low density, low viscosity, and high caloric properties, which makes it a better biofuel when contrasted to plant biofuel. Hence, this suggests that microalgae are more appropriate for biofuel than lignocellulosic materials [18]. However, four main steps are involved in the generation of algal-based products. These are algae cultivation, harvesting, processing, and extraction of the biomass. A flowchart of algal-based processing is illustrated in Fig. 1. In addition, despite the attractiveness of microalgae in simultaneous treatment of wastewater and biofuel production, microalgae culture, harvesting, and dewatering of microalgal biomass remain the main contributors to high costs of algal-based products $[19,20]$. Verily, these impede the commercial and sustainable microalgae production for 
biofuel generation in an economical, cost-effective with high yield and low energy manner [21]. Extensive studies have revealed ways of recovering culture medium for microalgae growth, such as combining cultivation and harvesting of microalgae in membrane photobioreactors [22,23]. Still yet, a cost-effective method of large scale harvesting is yet to be developed. Hence, this review presented and discussed current studies on microalgae cultivation and harvesting methods. As the microalgae harvesting stage is of critical importance, this review provides recent procedures for the cultivation and harvesting of microalgae, which have led to the identification of high rate algal ponds and photobioreactors as suitable systems for cultivation of microalgae. Also, different methods of microalgae recovery such as: flocculation, floatation, centrifugation, gravity sedimentation, screening, filtration, and as well as magnetic separation techniques have been discussed in the subsequent section.

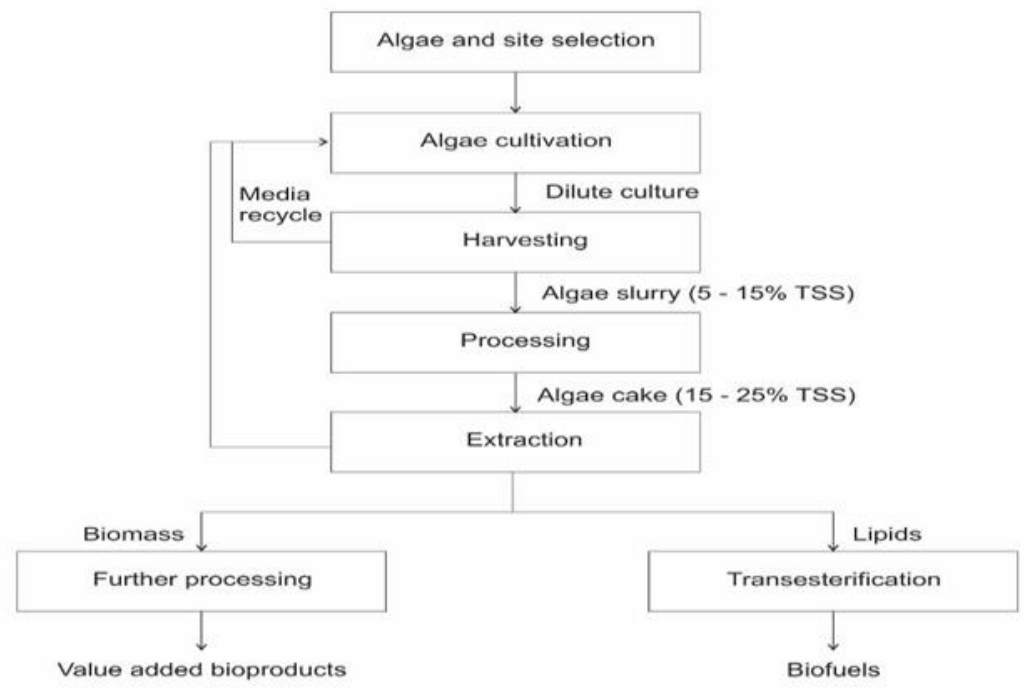

Figure 1. Flowchart of Algal-Based Biomass Processing [24,25].

\subsection{Microalgae Cultivation in Wastewater.}

The cultivation of microalgae in constructed wetlands meets all pre-requisites of ecofriendly purification processes for wastewater treatment because it offers better alternatives at low cost, and energy for the treatment processes meant for water reuse [26]. Furthermore, the cultivation of aquatic plants in wastewater for purification processes is more suitable in countries with warm climates. However, due to the advantages of this purification process, it postures to be a perfect solution for developing nations [27]. Moreover, several investigations have been carried out on nutrient recovery as well as the inherent ability of microalgae to develop on different composition of wastewater streams such as municipal wastewater and agro-industrial wastewater (animal wastes, food processing wastes and so on) $[28,29]$. For instance, microalgae (green growth) development in lakes and wastewater can be a financially beneficial and eco-friendly path for reasonable inexhaustible green growth based and bio-based compound generation since a large quantity of water, life cycle, and supplements needed for green growth development can adequately be conditioned into these systems [11]. It was further discovered that Phosphorous $(\mathrm{P})$ and Nitrogen $(\mathrm{N})$ nutrients supplements available in an assortment of wastewater sources could be utilized by green growth for bioremediation processes [10].

The development of green growth for feedstock generation can be accomplished either in open, closed, or hybrid techniques. The open techniques are more economical, but they are 
associated with limitations such as low contamination control from predators, while in closed systems, photobioreactors (PBR) can be utilized. PBR provides an ideal system that controls supplements and development parameters, for example, $\mathrm{pH}$, dissolved carbon dioxide $\left(\mathrm{CO}_{2}\right)$, temperature, and lighting at a high capital expense. Whereas, hybrid systems is the combination of both the open and closed systems in 2-way cultivation stages. Photobioreactors and open ponds are used to culture and develop the green growths in the first and second stages, respectively. However, the selection of a suitable technique relies on the intended use of the biomass, ecological conditions [30], and factors such as carbon, nitrogen, phosphorous and micronutrients, accessibility of supplements, temperature, $\mathrm{pH}$, light intensity, and aeration/agitation. Consequently, these components ought to be considered either in small or large quantities in the culture media to acquire superior advancement of the species and high yield of biomolecules of interest. Notwithstanding, despite the attractiveness related to generating biofuels from microalgae over higher plants, algal biofuels are yet to occupy a significant position in the global fossil fuel supply as various difficulties hampers the deployment of these bio-based fuels and has resulted in hindering the accomplishment of sustainable biofuel production from microalgae. To this end, several studies have been carried out in this area. Baudelet et al. [31] investigated the efficiency of Cladophora fracta, Cladophora glomerata, and Chlorophyta (green algae) in phytoremediation of wastewater and algal-based biomass generation. Similarly, Ansari et al. [32] investigated $\mathrm{CO}_{2}$ sequestration and biofuel production from wastewater treatment using local microalgae strains. The results presented indicated that excessive nutrients and chemical oxygen demand (COD) concentrations after 7 days of treatment were within the permissible standards of National Environmental Quality Standards (NEQs). Also, Leite et al. [33] cultivated microalgae in municipal and piggery wastewater samples collected from Brazil. The outcome of the investigations demonstrated that there was a significant ammonia $\left(\mathrm{NH}_{3}\right)$ evacuation via air stripping, diminishing the $\mathrm{N}$ : $\mathrm{P}$ proportion during the development, whereas, it subsequently affected the biomass profitability and supplement take-up. Further research was prescribed to diminish the $\mathrm{NH}_{3}$ stripping in order to improve green growth development and the treatment system. In a related development, Chew et al. [34] opined that various types of green growth are made up of the high substance of lipids appropriate for biofuels feedstock, while others that are suitable for food supplements have different applications.

In this regard, technologies comprising high rate algal ponds and photobioreactors have been utilized to ensure viable microalgae development for phytoremediation of wastewater and biomass recovery, which is further discussed in this review article.

\subsubsection{High Rate Algal Ponds.}

Microalgae cultivation technology such as high rate algal ponds (HRAP) has attracted new interest due to its low energy requirement for cultivation processes, wastewater treatment, and high yield of algal biomass generation [35]. The high rate algal ponds are made up of raceway ponds and a shallow paddlewheel and a raceway that enables the cultivated microalgae to assimilate nutrients and produce oxygen for oxidation of organic matter by bacteria [36]. However, they are considered natural systems that have a suitable way out for the treatment of wastewater, especially in small agglomerations with cheaper installation in areas with favorable weather conditions (e.g., temperature and high solar radiation). This technology has fewer environmental implications when contrasted with closed bioreactors and other conventional activated sludge systems [37,38]. Furthermore, one of the disadvantages 
hindering the spread and implementation of HRAPs technologies in wastewater reclamation is the wide-area space required for effective and efficient satisfactory removal of pollutants and biomass productivity [39]. Therefore, to conquer this major disadvantage, there is a need to simplify the operational system and maintenance of HRAP technologies by discarding the primary treatment from the entire operation. Several types of research conducted have revealed the potentials of HRAP technologies for phytoremediation of wastewater, feedstock productivity, and biofuels production. For instance, Arashiro et al. [40] studied the pilot-scale performance of two configurations of high rate algal ponds in wastewater treatment. The results obtained from the study indicated that the efficiency of the two configurated HRAP in the wastewater treatment was almost the same with the total suspended solids and volatile suspended solids concentration of the configurated HRAP without treatment higher than that of HRAP with treatment. Furthermore, the Authors postulated the change observed between the two systems was due to the higher inert solids concentration discharged into the HRAP without treatment than in the microorganism biomass. These results corroborated previous studies, where efficient wastewater treatment was obtained when microalgae were cultivated in various stages of domestic wastewater plants $[41,42]$. Besides, the dismissal of primary treatment preceding in HRAP method is a dispensable step as this would simplify the operations, alongside reducing costs and footprint in HRAP technologies [40].

\subsubsection{Photobioreactors.}

Photobioreactors are types of bioreactors that rely on the light source to cultivate phototrophic microorganisms like microalgae. The yield of microalgae biomass is the primary factor deciding the choice of the reactor to be used as a cultivation process. There are several photobioreactors (namely column, flat plate, tabular, and membrane photobioreactors designed for microalgae cultivation [30]. However, the effectiveness of photobioreactors in the cultivation of microalgae simply relies on the availability of light illumination and other parameters such as carbon dioxide feed, cultivation medium feed, circulation system, and capital cost. Though, the cultivation of microalgae in photobioreactors has an advantage of simple operations, higher yield of biomass, and low contamination rate than other cultivation systems. Several findings on applications of various types of photobioreactors in the development of microalgae for phytoremediation of wastewater and biomass production have been reported. Westerwalbesloh et al. [43] developed and examined a microfluidic photobioreactor for the cultivation of Chlorella sorokiniana. The findings obtained from the studies indicated that the microbioreactor could improve the growth of algae under regulated temperature and adjustable lighting over a series of photon influx densities. In addition, the developed microbioreactor can be useful for thorough evaluation studies of microalgae in a large scale at a laboratory under well-defined medium composition and lighting. Similarly, Asthary et al. [44] compared the development of Spirulina platensis in an open pond system and tubular photobioreactor using wastewater sample and $\mathrm{CO}_{2}$ emission of a paper mill. The conducted research has shown that biomass obtained from the tubular photobioreactor was three times greater than the biomass derived from the open pond system. This implies that photobioreactor is more efficient in the generation of biomass than the open pond system. Furthermore, Pacheco et al. [45] studied the efficiency of secondary wastewater treatment using microalgae cultivated in a mixed type photobioreactor system. The results obtained from this research conclude that the use of a mixed-type photobioreactor is a promising alternative technique for phytoremediation of wastewater and biomass generation. 


\subsection{Harvesting of algae biomass.}

After the development of microalgae in a culture media for a stipulated time, the next process is the harvest of the microalgae biomass for further analysis and applications. Microalgae harvesting is essential to extract useful algal biomass for further processing and applications in biofuels generation and other valuable products. Different methods of microalgae recovery such as centrifugation, flocculation, floatation, filtration, gravity sedimentation, screening, and magnetic separation techniques have been extensively studied for pilot and large scale harvesting of algal biomass [46]. Hence, the subsequent section of this study provides comprehensive discussions on various methods of microalgae harvesting due to their promising disposition reported from previous studies. Also, the merits and demerits of these harvesting techniques have been highlighted. These methods were selected due to their promising efficiency, economic viability, and prospects in generating eco-friendly algal biomass recovery techniques that will lead to large scale biofuel production.

\subsubsection{Flocculation.}

The technique of flocculation is reported as a successful approach used to harvest different species of microalgae [47,48]. It requires the application of flocculants to form aggregation or clumps of small and unstable constituent via surface charge, electrostatic patching neutralization, or bridging. Therefore, flocculation is a technique whereby small algal cells aggregates together through the use of chemicals to form larger clumps. In other words, the formation of the floc promotes easy separation/recovery process through any conventional methods (filtration, floatation) or simple gravity-induced settling. The flocculation medium simply depends on the type of coagulants (flocculant), microalgae species, cell concentrations, $\mathrm{pH}$ level, charge densities, growth phase, and so forth [49]. However, various types of chemicals like metallic salts, polymers (cationic starch and poly-diallyl dimethylammonium chloride), chitosan, $\mathrm{pH}$-induced, and cetyl tetramethyl ammonium bromide have been used as coagulants in flocculation methods of algae harvesting [50-52]. The selection of flocculants simply depends on factors relating to the algae strain, cultivation process, and conversion processes involved in the harvested algal biomass into biofuels [53]. The application of chemical coagulants such as metallic salts has a potential limitation in their usage when the chemicals contaminate the harvested algal biomass and, as such, affect further end uses of the microalgal biomass $[54,55]$.

Similarly, the utilization of some synthetic coagulants may negatively influence biochemical compounds like proteins, starch, and lipids [56], prompting unlikelihood for food or nutrition production. Hence, the selection of suitable flocculants is particularly imperative, because it must not influence on subsequent products [24,57]. Therefore, natural coagulants such as chitosan, guar gum, groundnuts powder, and Moringa oleifera seed flour can be employed for harvesting microalgal biomass [58,59]. In addition, flocculation is believed to be a simple, low cost and preferable method that enables culture medium recovery without energy requirements [60]. Flocculation techniques are subdivided into chemical, autoflocculation, and physical flocculation methods. Soomro et al. [61] developed a two-stage dewatering process of microalgae in order to evaluate the effectiveness of various dewatering techniques. The dewatering techniques studied are centrifugation, electrocoagulation and centrifugation, alum flocculation and centrifugation, magnetic separation and filtration (TFF), and bioflocculation and TFF. The study also compared the energy life cycle and carbon dioxide life cycle of the 
dewatering techniques for likely applications in industrial scale algal biofuel generation. The findings indicated that bioflocculation combined with tangential flow filtration (TFF) has resulted into a viable approach with a budget of $\$ 0.0043$, the energy consumption of 0.042 $\mathrm{kWh}$, and $0.05 \mathrm{~kg}$ carbon emissions to generate $1 \mathrm{~kg}$ of microalgae biomass. Zhu et al. [62] evaluated and compared the performance of chitosan (natural flocculants) and aluminum sulfate (traditional flocculants) to extract microalgae Chlorella vulgaris biomass. The results presented indicated that chitosan is appropriate for microalgal harvesting as $90 \%$ biomass recovery was accomplished. In this vein, further study is required to develop natural flocculants from non-edible plant products that are inexpensive and eco-friendly.

\subsubsection{Filtration.}

Filtration is a dewatering procedure applied after flocculation to improve harvesting efficiency. A membrane film is usually used in the process to recover algal biomass from the culture media so that the algae biomass residue is collected on the film. At the same time, the liquid passes through the membrane film under a pressure variation in the filter, which can be determined by gravity, pressure, or vacuum. Different kinds of filtration procedures, for example, pressure, vacuum, and cross-flow filtrations, have been utilized for microalgal harvesting. However, the function of this process for algal biomass recovery always suffers from fouling or clogging, especially at high biomass concentration, which is time-consuming and rendering its practicality [63]. This denotes the major shortcoming associated with filtration methods, thereby increasing the operational cost [64]. Limitations of the filtration process of harvesting include slow operation, high operating, and maintenance cost [24]. In addition, ultra and microfiltration membranes allow higher filtration rates through the complete removal of microalgal debris and cells. Microfiltration membrane having a pore size of 0.1 to $10 \mu \mathrm{m}$ can be used to harvest delicate tiny cells. However, these categories of the membrane allow higher initial fluxes but clog more easily [46]. In other words, ultrafiltration with a pore diameter ranging from 1-100 $\mathrm{nm}$ is suitable for separating solutes of molecular weight within 1-500 $\mathrm{kDa}$. In this respect, the effectiveness of these techniques appear to be expensive, energyintensive driven and requires frequent membrane replacements [65]. Though the filtration process allows high recovery efficiencies and the parting of shear sensitive species, the membranes must be routinely cleaned and disinfected. Fasaei et al. [20] Examined the technoeconomic study of various industrial-scale dewatering and harvesting methods of microalgae. The results obtained from the study showed that single-step filtration methods are very attractive due to their low cost and ease of operations, but the risk of fouling hinders its performance in higher product concentrations. Alternative filtration can be executed using a two-stage method involving an effective step like spiral plate technology or centrifugation. For instance, membrane filtration accompanied by centrifugation is less expensive than the combination of membrane filtration with spiral plate technology, whereas vacuum filtration is seen to be more efficient as a single step compared to the combining vacuum filtration with a dewatering step.

\subsubsection{Floatation.}

Floatation method of microalgae harvesting is feasible for large scale purposes with a lower cost method, but they require the application of coagulants. Flotation techniques of algal biomass harvesting involve the pumping of air bubbles beneath a sedimentation tank to aid 
gravity separation of algal biomass. This method is particularly useful in the recovery process, whereby the settling velocity of the algae is insignificant for gravitational separation. The floating power of the air bubbles and particulate matter enables them to rise to the surface, creating a film of thickened slurry that could be gathered through the skimming method [66]. In most cases, an optimum dose of coagulant is needed for the efficient harvesting of algal biomass [67]. Coagulants like polymers and ferric salts are used to allow flotation techniques to increase allowable solid loadings, and clarity of the effluents. This method offers higher solids concentrations at lower initial equipment costs. Dissolved-air, electro-floatation, dispersed air, and ozone floatation are the major types of flotation techniques used in algal biomass harvesting. Small air bubbles sizing from 10-100 $\mu \mathrm{m}$ are used in the dissolved air floatation method, whereby these bubbles force/push solid microalgae cells to rise to the surface in order to be collected through the skimming method. These make the dissolved air method tedious and an energy-intensive process. While air bubbles ranging from 700 to 1500 $\mu \mathrm{m}$ produced from powerful mechanical agitators are used in the dispersed air floatation method. However, this technique consumes less energy but requires high maintenance costs [68]. Zou et al. [69] carried out buoy-bead flotation (BBF) process combined with chitosan pre-flocculation using natural flocculant as alternatives to conventional coagulants in order to enhance the harvesting performance of Scenedesmus obliquus and Chlorella vulgaris. The results obtained from the study showed that the BBF method yield harvesting efficiencies of $83.77 \%$ Scenedesmus obliquus and $92.47 \%$ Chlorella vulgaris.

\subsubsection{Centrifugation.}

The centrifugal method is a mechanical process known as the most reliable and fastest method of algal harvesting from a cultured media and a wide range of microalgal species. It is usually used for pharmaceuticals, saturated fatty acids, and other high valued products [70] because they possess the capacity to regain the greater part of microalgae biomass [65]. The quality of the whole process, therefore, relies on the rotational speed used in the separation of solids suspended in a liquid [71], which gives it the ability to recover the greater part of the algal biomass from the culture media. Nozzle type, solid bowl decanter, and solid ejecting disc discharge are examples of centrifugation devices used in algal biomass recovery. According to reports, centrifugation devices can be used as a one-step separation process, while others are inefficient and requires preconcentration of the algal slurry [64]. However, this technique is time-consuming and costly due to its high energy requirement (about $3000 \mathrm{Wht}^{-1}$ ), and also, there is a tendency that the mechanical spinning of the microalgal cell through high shear and gravitational forces might result to the destruction of the cell structures [72]. Centrifugation method is usually performed at a laboratory or pilot scale and some of the advantages of using this method include; efficiency and do not involve the use of chemicals that may infiltrate the finished product. Wang et al. [23] carried out wastewater treatment by cultivating two microalgae species (Chlorella sp. and S. platensis) in poultry wastewater using the two-stage method for simultaneous treatment of the wastewater and biomass extraction. According to the study, Chlorella sp. was harvested using the centrifugation method in the first stage, followed by the cultivation of $S$. platensis in the second stage of the cultivation. The findings obtained for the wastewater remediation shows that the percentage removal efficiencies of $\mathrm{NH}_{4}^{+}$, total phosphorous, and total organic carbon reached $19 \%$ and $100 \%, 17 \%$ and $83 \%$, and $55 \%$ and $72 \%$ in the first and second stage, respectively while the biomass yield of $0.39 \mathrm{~g} / \mathrm{L}$ and 3.45 $\mathrm{g} / \mathrm{L}$ was generated for Chlorella $s p$. and $S$. platensis, respectively. 


\subsubsection{Gravity Sedimentation.}

The process of gravity sedimentation method can be used to extract dense freshwater algae species from wastewater cultured algae systems. It involves the use of large settling tanks and lamella separators for the recovery of algae in large scale wastewater treatment systems $[73,74]$. This method of harvesting microalgae yields a wet, high quantity of sludge, resulting from slow settling and poor compaction velocities [73]. Generally, the success of this method relies on the light intensity, size, and weight of the microalgae, temperature, time, and induced sedimentation velocity $[71,73]$. The use of sedimentation tanks in this process is simple, cheap and requires low energy, but it is slow and produces a low yield of algal biomass, especially when the algae cultured did not undergo the coagulation process. In other words, to enhance microalgal removal and settling, the coagulation step should be applied to algae concentrations before the gravity sedimentation method [75]. However, Trovão et al. [76] evaluated the biochemical composition, growth performance, and settling velocity of Tetraselmis sp. $\mathrm{CTP}_{4}$ in varying salinity conditions with a view to achieving a cost-effective harvesting method. The results observed from the study show that identical settling velocities of 2.4 to $3.6 \mathrm{~cm} / \mathrm{h}$ were recorded on all salinities $(5,10$, and $20 \mathrm{~g} / \mathrm{L} \mathrm{NaCl})$ under lab-scale study. While in the tubular photobioreactor, algal cell sedimentation resulted in the recovery of $93 \%$ of the culture medium in the form of liquid containing a vestigial quantity of $0.07 \pm 0.02 \mathrm{~g} / \mathrm{L}$ dry weight biomass. The authors concluded that the sedimentation method under salinity conditions enabled a high yield of $97 \%$ of the algal biomass at a considerably low cost.

\subsubsection{Magnetic Separation.}

Magnetic separation method has emerged as a promising technique in microalgal harvesting, owing to its ease of operation, reduced energy requirement, low cost of operation, small land size requirement, no fouling and clogging problems, and high permeation fluxes [77,78]. Also, in magnetic separation, the particle surface modification, magnetic particle concentration, and $\mathrm{pH}$ of the surroundings are crucial in microalgae biomass harvesting [79]. The major limitation of this technology, however, is the high cost of nano-magnetic particles and poor adsorption strength that is often encountered on the magnetic separation framework [80]. In addition, magnetic material could be easily isolated in a mixture with a magnetic component with permanent magnets or electro-magnets particles. Adsorption is caused by electrostatic attractions between magnetic particles and microalgae cells, affecting stirring velocity, magnetic dose, flow rate, $\mathrm{pH}$ suspension, hydrodynamic resistance, and magnetic field strength [81]. Hence, Japar et al. [82] examined the application of different techniques of harvesting microalgae biomass by assessing the efficiency of three harvesting methods (magnetic separation, centrifugation, and sedimentation) by using microalgae species isolated from palm oil mill effluent. The results obtained indicated that centrifugation method exhibited the best performance with $98 \%$ harvesting efficiency at a rotational speed of $7000 \mathrm{rpm}$ per 5 minutes, while sedimentation using alum (aluminum sulfate) gave the lowest efficiency of $76 \%$ after 8 hours and magnetic separation using iron oxide nanoparticles (IONPs) showed $94 \%$ harvesting efficiency. This results entails that the centrifugation method is more suitable for the harvesting of microbial biomass owing to its high performance and most commercially feasible technique. 


\section{Conclusion}

Recent advances in applications of photobioreactors and high rate algal ponds in microalgae cultivation for the combined bioremediation of wastewater and feedstock generation have been researched and documented. On this note, current studies on microalgae cultivation and harvesting methods have been presented and discussed. However, in the course of this study, high rate algal ponds and photobioreactors were found to be a reliable system for the cultivation of microalgae and wastewater treatment. Hence, the two-step method of dewatering methods is found to be the most effective approach for microalgae cultivation for wastewater treatment and generation of algal-based feedstock, taking into account high yield potentials and commercial factors such as cost of operation and energy required for large scale algal biomass processing for biofuel generations. Furthermore, it can be deduced that the development of microalgae for the purposes of wastewater management and biofuel production appears as a promising venture if constraints that are associated with the processes such as the selection of suitable microalgae strains, the sensitivity of managing strains of microalgae for maximum growth, resultant low quantity of biomass obtained after cultivation, complications in biomass extractions, high cost of photobioreactors, and large space requirement for high rate algal ponds are effectively overcome. These complications have driven the utilization of microalgae for these purposes tedious and less attractive.

\section{Funding}

This research was funded by UNITEN BOLD2025, grant number 10436494/B/2019136 from Universiti Tenaga Nasional (UNITEN).

\section{Acknowledgments}

This research has no acknowledgment.

\section{Conflicts of Interest}

The authors declare no conflict of interest.

\section{References}

1. Mostafa, S.S.M.; Shalaby, E.A.; Mahmoud, G.I. Cultivating Microalgae in Domestic Wastewater for Biodiesel Production. Not. Sci. Biol. 2012, 4, 56-65, https://doi.org/10.15835/nsb417298.

2. Alipoor, A.; Saidi, M.H. Numerical study of hydrogen-air combustion characteristics in a novel microthermophotovoltaic power generator. Appl. Energy 2017, 199, 382-399, https://doi.org/10.1016/j.apenergy.2017.05.027.

3. Frouzakis, C.E.; Fogla, N.; Tomboulides, A.G.; Altantzis, C.; Matalon, M. Numerical study of unstable hydrogen/air flames: Shape and propagation speed. Proc. Combust. Inst. 2015, 35, 1087-1095, https://doi.org/10.1016/j.proci.2014.05.132.

4. Ansari, A.J.; Hai, F.I.; Price, W.E.; Drewes, J.E.; Nghiem, L.D. Forward osmosis as a platform for resource recovery from municipal wastewater - A critical assessment of the literature. J. Memb. Sci. 2017, 529, 195206, https://doi.org/10.1016/j.memsci.2017.01.054.

5. Kaza, S.; Yao, L.C.; Bhada-Tata, P.; van Woerden, F. What a Waste 2.0: A global snapshot of solid waste management to 2050. Washington, 2018.

6. WHO/UNICEF No Title. https://www.unwater.org/water-facts/quality-and-wastewater accessed 5 Sept. 2019, 2015.

7. Ozturk, M.; Saba, N.; Altay, V.; Iqbal, R.; Hakeem, K.R.; Jawaid, M.; Ibrahim, F.H. Biomass and bioenergy: An overview of the development potential in Turkey and Malaysia. Renew. Sustain. Energy Rev. 2017, 79, 1285-1302, https://doi.org/10.1016/j.rser.2017.05.111.

8. Lee, R.A.; Lavoie, J.M. From first- to third-generation biofuels: Challenges of producing a commodity from 
a biomass of increasing complexity. Anim. Front. 2013, 3, 6-11, https://doi.org/10.2527/af.2013-0010.

9. Rawat, I.; Ranjith Kumar, R.; Mutanda, T.; Bux, F. Biodiesel from microalgae: A critical evaluation from laboratory to large scale production. Appl. Energy 2013, 103, 444-467, https://doi.org/10.1016/j.apenergy.2012.10.004.

10. Chinnasamy, S.; Bhatnagar, A.; Claxton, R.; Das, K.C. Biomass and bioenergy production potential of microalgae consortium in open and closed bioreactors using untreated carpet industry effluent as growth medium. Bioresour. Technol. 2010, 101, 6751-6760, https://doi.org/10.1016/j.biortech.2010.03.094.

11. Zhou, W.; Li, Y.; Min, M.; Hu, B.; Zhang, H.; Ma, X.; Li, L.; Cheng, Y.; Chen, P.; Ruan, R. Growing wastewater-born microalga Auxenochlorella protothecoides UMN280 on concentrated municipal wastewater for simultaneous nutrient removal and energy feedstock production. Appl. Energy 2012, 98, 433440, https://doi.org/10.1016/j.apenergy.2012.04.005.

12. Hu, B.; Min, M.; Zhou, W.; Du, Z.; Mohr, M.; Chen, P.; Zhu, J.; Cheng, Y.; Liu, Y.; Ruan, R. Enhanced mixotrophic growth of microalga Chlorella sp. on pretreated swine manure for simultaneous biofuel feedstock production and nutrient removal. Bioresour. Technol. 2012, 126, 71-79, https://doi.org/10.1016/j.biortech.2012.09.031.

13. Mehta, P.; Singh, D.; Saxena, R.; Rani, R.; Gupta, R.P.; Puri, S.K.; Mathur, A.S. High-Value Coproducts from Algae-An Innovational Way to Deal with Advance Algal Industry. 2018, 343-363, https://doi.org/10.1007/978-981-10-7431-8_15.

14. Najafi, G.; Ghobadian, B.; Yusaf, T.F. Algae as a sustainable energy source for biofuel production in Iran: A case study. Renew. Sustain. Energy Rev. 2011, 15, 3870-3876, https://doi.org/10.1016/j.rser.2011.07.010.

15. Yahya, N.A.; Attan, N.; Wahab, R.A. An overview of cosmeceutically relevant plant extracts and strategies for extraction of plant-based bioactive compounds. Food Bioprod. Process. 2018, 112, 69-85, https://doi.org/10.1016/j.fbp.2018.09.002.

16. Vo Hoang Nhat, P.; Ngo, H.H.; Guo, W.S.; Chang, S.W.; Nguyen, D.D.; Nguyen, P.D.; Bui, X.T.; Zhang, X.B.; Guo, J.B. Can algae-based technologies be an affordable green process for biofuel production and wastewater remediation? Bioresour. Technol. 2018, 256, 491-501, https://doi.org/10.1016/j.biortech.2018.02.031.

17. Chisti, Y. Biodiesel from microalgae. Biotechnol. Adv. 2007, 25, 294-306, https://doi.org/10.1016/j.biotechadv.2007.02.001.

18. Miao, X.; Wu, Q.; Yang, C. Fast pyrolysis of microalgae to produce renewable fuels. J. Anal. Appl. Pyrolysis 2004, 71, 855-863, https://doi.org/10.1016/j.jaap.2003.11.004.

19. Ruiz, J.; Olivieri, G.; De Vree, J.; Bosma, R.; Willems, P.; Reith, J.H.; Eppink, M.H.M.; Kleinegris, D.M.M.; Wijffels, R.H.; Barbosa, M.J. Towards industrial products from microalgae. Energy Environ. Sci. 2016, 9, 3036-3043, https://doi.org/10.1039/c6ee01493c.

20. Fasaei, F.; Bitter, J.H.; Slegers, P.M.; van Boxtel, A.J.B. Techno-economic evaluation of microalgae harvesting and dewatering systems. Algal Res. 2018, 31, 347-362, https://doi.org/10.1016/j.algal.2017.11.038.

21. Lei, X.; Chen, Y.; Shao, Z.; Chen, Z.; Li, Y.; Zhu, H.; Zhang, J.; Zheng, W.; Zheng, T. Effective harvesting of the microalgae Chlorella vulgaris via flocculation-flotation with bioflocculant. Bioresour. Technol. 2015, 198, 922-925, https://doi.org/10.1016/j.biortech.2015.08.095.

22. Bilad, M.R.; Arafat, H.A.; Vankelecom, I.F.J. Membrane technology in microalgae cultivation and harvesting: $\quad \mathrm{A}$ review. Biotechnol. Adv. 2014, $32, \quad$ 1283-1300, https://doi.org/10.1016/j.biotechadv.2014.07.008.

23. Wang, X.; Lin, L.; Lu, H.; Liu, Z.; Duan, N.; Dong, T.; Xiao, H.; Li, B.; Xu, P. Microalgae cultivation and culture medium recycling by a two-stage cultivation system. Front. Environ. Sci. Eng. 2018, 12, 1-10, https://doi.org/10.1007/s11783-018-1078-z.

24. Laamanen, C.A.; Ross, G.M.; Scott, J.A. Flotation harvesting of microalgae. Renew. Sustain. Energy Rev. 2016, 58, 75-86, https://doi.org/10.1016/j.rser.2015.12.293.

25. Mata, T.M.; Martins, A.A.; Caetano, N.S. Microalgae for biodiesel production and other applications: A review. Renew. Sustain. Energy Rev. 2010, 14, 217-232, https://doi.org/10.1016/j.rser.2009.07.020.

26. Kadlec, R.H; Wallace, S.. Treatment Wetlands. 2nd ed.; CRC Press, Boca Raton, RF, 2009.

27. Zhang, D.Q.; Jinadasa, K.B.S.N.; Gersberg, R.M.; Liu, Y.; Ng, W.J.; Tan, S.K. Application of constructed wetlands for wastewater treatment in developing countries - A review of recent developments (2000-2013). J. Environ. Manage. 2014, 141, 116-131, https://doi.org/10.1016/j.jenvman.2014.03.015.

28. Van Den Hende, S.; Beyls, J.; De Buyck, P.J.; Rousseau, D.P.L. Food-industry-effluent-grown microalgal bacterial flocs as a bioresource for high-value phycochemicals and biogas. Algal Res. 2016, 18, 25-32, https://doi.org/10.1016/j.algal.2016.05.031.

29. Abinandan, S.; Shanthakumar, S. Challenges and opportunities in application of microalgae (Chlorophyta) for wastewater treatment: A review. Renew. Sustain. Energy Rev. 2015, 52, 123-132, https://doi.org/10.1016/j.rser.2015.07.086.

30. Moreno-Garcia, L.; Adjallé, K.; Barnabé, S.; Raghavan, G.S.V. Microalgae bio mass production for a biorefinery system: Recent advances and the way towards sustainability. Renew. Sustain. Energy Rev. 2017, 76, 493-506, https://doi.org/10.1016/j.rser.2017.03.024. 
31. Baudelet, P.H.; Ricochon, G.; Linder, M.; Muniglia, L. A new insight into cell walls of Chlorophyta. Algal Res. 2017, 25, 333-371, https://doi.org/10.1016/j.algal.2017.04.008.

32. Ansari, A.A.; Khoja, A.H.; Nawar, A.; Qayyum, M. Wastewater treatment by local microalgae strains for CO 2 sequestration and biofuel production. Appl. Water Sci. 2017, 7, 4151-4158, https://doi.org/10.1007/s13201-017-0574-9.

33. Leite, L. de S.; Hoffmann, M.T.; Daniel, L.A. Microalgae cultivation for municipal and piggery wastewater treatment in Brazil. J. Water Process Eng. 2019, 31, 1-7, https://doi.org/10.1016/j.jwpe.2019.100821.

34. Chew, K.W.; Chia, S.R.; Show, P.L.; Yap, Y.J.; Ling, T.C.; Chang, J.S. Effects of water culture medium, cultivation systems and growth modes for microalgae cultivation: A review. J. Taiwan Inst. Chem. Eng. 2018, 91, 332-344, https://doi.org/10.1016/j.jtice.2018.05.039.

35. Young, P.; Taylor, M.; Fallowfield, H.J. Mini-review: high rate algal ponds, flexible systems for sustainable wastewater treatment. World J. Microbiol. Biotechnol. 2017, 33, https://doi.org/10.1007/s11274-017-2282$\mathrm{X}$.

36. Craggs, R.; Park, J.; Heubeck, S.; Sutherland, D. High rate algal pond systems for low-energy wastewater treatment, nutrient recovery and energy production. New Zeal. J. Bot. 2014, 52, 60-73, https://doi.org/10.1080/0028825X.2013.861855.

37. Garfí, M.; Flores, L.; Ferrer, I. Life Cycle Assessment of wastewater treatment systems for small communities: Activated sludge, constructed wetlands and high rate algal ponds. J. Clean. Prod. 2017, 161, 211-219, https://doi.org/10.1016/j.jclepro.2017.05.116.

38. Delrue, F.; Álvarez-Díaz, P.D.; Fon-Sing, S.; Fleury, G.; Sassi, J.F. The environmental biorefinery: Using microalgae to remediate wastewater, a win-win paradigm. Energies 2016, 9, 1-19, https://doi.org/10.3390/en9030132.

39. Acién, F.G.; Gómez-Serrano, C.; Morales-Amaral, M.M.; Fernández-Sevilla, J.M.; Molina-Grima, E. Wastewater treatment using microalgae: how realistic a contribution might it be to significant urban wastewater treatment? Appl. Microbiol. Biotechnol. 2016, 100, 9013-9022, https://doi.org/10.1007/s00253016-7835-7.

40. Arashiro, L.T.; Ferrer, I.; Rousseau, D.P.L.; Van Hulle, S.W.H.; Garfí, M. The effect of primary treatment of wastewater in high rate algal pond systems: Biomass and bioenergy recovery. Bioresour. Technol. 2019, 280, 27-36, https://doi.org/10.1016/j.biortech.2019.01.096.

41. Cabanelas, I.T.D.; Ruiz, J.; Arbib, Z.; Chinalia, F.A.; Garrido-Pérez, C.; Rogalla, F.; Nascimento, I.A.; Perales, J.A. Comparing the use of different domestic wastewaters for coupling microalgal production and nutrient removal. Bioresour. Technol. 2013, 131, 429-436, https://doi.org/10.1016/j.biortech.2012.12.152.

42. Kong, Q.X.; Li, L.; Martinez, B.; Chen, P.; Ruan, R. Culture of microalgae chlamydomonas reinhardtii in wastewater for biomass feedstock production. Appl. Biochem. Biotechnol. 2010, 160, 9-18, https://doi.org/10.1007/s12010-009-8670-4.

43. Westerwalbesloh, C.; Brehl, C.; Weber, S.; Probst, C.; Widzgowski, J.; Grünberger, A.; Pfaff, C.; Nedbal, L.; Kohlheyer, D. A microfluidic photobioreactor for simultaneous observation and cultivation of single microalgal cells or cell aggregates. PLoS One 2019, 14, 1-13, https://doi.org/10.1371/journal.pone.0216093.

44. Asthary, P.B.; Saepulloh; Pramono, K.J.; Rachmanto, T.; Setiawan, Y. Cultivation of Spirulina platensis using WWTP effluent and CO2 emission of papermill in tubular photobioreactor. AIP Conf. Proc. 2019, 2120, https://doi.org/10.1063/1.5115669.

45. Pacheco, M.M.; Hoeltz, M.; Bjerk, T.R.; de Souza, M.P.; da Silva, L.F.F.; Gressler, P.D.; Moraes, M.S.A.; Lobo, E.A.; Schneider, R.C.S. Evaluation of microalgae growth in a mixed-type photobioreactor system for the phycoremediation of wastewater. J. Chem. Technol. Biotechnol. 2019, 94, 3102-3110, https://doi.org/10.1002/jctb.6117.

46. Uduman, N.; Qi, Y.; Danquah, M.K.; Forde, G.M.; Hoadley, A. Dewatering of microalgal cultures: A major bottleneck to algae-based fuels. J. Renew. Sustain. Energy 2010, 2, https://doi.org/10.1063/1.3294480.

47. Wan, C.; Alam, M.A.; Zhao, X.Q.; Zhang, X.Y.; Guo, S.L.; Ho, S.H.; Chang, J.S.; Bai, F.W. Current progress and future prospect of microalgal biomass harvest using various flocculation technologies. Bioresour. Technol. 2015, 184, 251-257, https://doi.org/10.1016/j.biortech.2014.11.081.

48. Matter, I.A.; Hoang Bui, V.K.; Jung, M.; Seo, J.Y.; Kim, Y.E.; Lee, Y.C.; Oh, Y.K. Flocculation harvesting techniques for microalgae: A review. Appl. Sci. 2019, 9, https://doi.org/10.3390/app9153069.

49. Ndikubwimana, T.; Zeng, X.; Murwanashyaka, T.; Manirafasha, E.; He, N.; Shao, W.; Lu, Y. Harvesting of freshwater microalgae with microbial bioflocculant: A pilot-scale study. Biotechnol. Biofuels 2016, 9, 1-11, https://doi.org/10.1186/s13068-016-0458-5.

50. Reyes, J.F.; Labra, C. Biomass harvesting and concentration of microalgae scenedesmus sp. cultivated in a pilot phobioreactor. Biomass and Bioenergy 2016, 87, 78-83, https://doi.org/10.1016/j.biombioe.2016.02.014.

51. Hansel, P.A.; Guy Riefler, R.; Stuart, B.J. Efficient flocculation of microalgae for biomass production using cationic starch. Algal Res. 2014, 5, 133-139, https://doi.org/10.1016/j.algal.2014.07.002.

52. Gerchman, Y.; Vasker, B.; Tavasi, M.; Mishael, Y.; Kinel-Tahan, Y.; Yehoshua, Y. Effective harvesting of microalgae: Comparison of different polymeric flocculants. Bioresour. Technol. 2017, 228, 141-146, https://doi.org/10.1016/j.biortech.2016.12.040. 
53. Donev, J; Stenhouse, K; Afework, B. Energy Education-Harvesting algae 2018 [Online]. https://energyeducation.ca/encyclopedia/Harvesting_algae. Accessed 14 August 2019

54. Ahmad, A.L.; Mat Yasin, N.H.; Derek, C.J.C.; Lim, J.K. Optimization of microalgae coagulation process using chitosan. Chem. Eng. J. 2011, 173, 879-882, https://doi.org/10.1016/j.cej.2011.07.070.

55. Rashid, N.; Rehman, M.S.U.; Han, J.I. Use of chitosan acid solutions to improve separation efficiency for harvesting of the microalga Chlorella vulgaris. Chem. Eng. J. 2013, 226, 238-242, https://doi.org/10.1016/j.cej.2013.04.062.

56. Ummalyma, S.B.; Mathew, A.K.; Pandey, A.; Sukumaran, R.K. Harvesting of microalgal biomass: Efficient method for flocculation through $\mathrm{pH}$ modulation. Bioresour. Technol. 2016, 213, 216-221, https://doi.org/10.1016/j.biortech.2016.03.114.

57. Vandamme, D.; Foubert, I.; Muylaert, K. Flocculation as a low-cost method for harvesting microalgae for bulk biomass production. Trends Biotechnol. 2013, 31, 233-239, https://doi.org/10.1016/j.tibtech.2012.12.005.

58. Fast, S.A.; Kokabian, B.; Gude, V.G. Chitosan enhanced coagulation of algal turbid waters - Comparison between rapid mix and ultrasound coagulation methods. Chem. Eng. J. 2014, 244, 403-410, https://doi.org/10.1016/j.cej.2014.01.081.

59. Teixeira, C.M.L.L.; Kirsten, F.V.; Teixeira, P.C.N. Evaluation of Moringa oleifera seed flour as a flocculating agent for potential biodiesel producer microalgae. J. Appl. Phycol. 2012, 24, 557-563, https://doi.org/10.1007/s10811-011-9773-1.

60. Liu, C.; Hao, Y.; Jiang, J.; Liu, W. Valorization of untreated rice bran towards bioflocculant using a lignocellulose-degrading strain and its use in microalgal biomass harvest. Biotechnol. Biofuels 2017, 10, 112, https://doi.org/10.1186/s13068-017-0780-6.

61. Soomro, R.R.; Ndikubwimana, T.; Zeng, X.; Lu, Y.; Lin, L.; Danquah, M.K. Development of a two-stage microalgae dewatering process - A life cycle assessment approach. Front. Plant Sci. 2016, 7, 1-12, https://doi.org/10.3389/fpls.2016.00113.

62. Zhu, L.; Li, Z.; Hiltunen, E. Microalgae Chlorella vulgaris biomass harvesting by natural flocculant: Effects on biomass sedimentation, spent medium recycling and lipid extraction. Biotechnol. Biofuels 2018, 11, 110, https://doi.org/10.1186/s13068-018-1183-z.

63. Farahah Mohd Khairuddin, N.; Idris, A.; Irfan, M.; Bahru, J. Towards Efficient Membrane Filtration for Microalgae Harvesting: A Review (Menuju Filtrasi Membran yang Cekap untuk Penuaian Mikroalga: Kajian Semula). J. Kejuruter. SI 2019, 2, 103-112.

64. Christenson, L.; Sims, R. Production and harvesting of microalgae for wastewater treatment, biofuels, and bioproducts. Biotechnol. Adv. 2011, 29, 686-702, https://doi.org/10.1016/j.biotechadv.2011.05.015.

65. Rawat, I.; Ranjith Kumar, R.; Mutanda, T.; Bux, F. Dual role of microalgae: Phycoremediation of domestic wastewater and biomass production for sustainable biofuels production. Appl. Energy 2011, 88, 3411-3424, https://doi.org/10.1016/j.apenergy.2010.11.025.

66. Chen, Y.M.; Liu, J.C.; Ju, Y.H. Flotation removal of algae from water. Colloids Surfaces B Biointerfaces 1998, 12, 49-55, https://doi.org/10.1016/S0927-7765(98)00059-9.

67. Bare, W.F.R.; Jones, N.B.; Middlebrooks, E.J.; Rance, F.; Middlebrooks, J. Removal Algae air flotation using dissolved. 2015, 47, 153-169.

68. Chen, C.Y.; Yeh, K.L.; Aisyah, R.; Lee, D.J.; Chang, J.S. Cultivation, photobioreactor design and harvesting of microalgae for biodiesel production: A critical review. Bioresour. Technol. 2011, 102, 71-81, https://doi.org/10.1016/j.biortech.2010.06.159.

69. Zou, X.; Li, Y.; Xu, K.; Wen, H.; Shen, Z.; Ren, X. Microalgae harvesting by buoy-bead flotation process using Bioflocculant as alternative to chemical flocculant. Algal Res. 2018, 32, 233-240, https://doi.org/10.1016/j.algal.2018.04.010.

70. Zhou, W.; Min, M.; Hu, B.; Ma, X.; Liu, Y.; Wang, Q.; Shi, J.; Chen, P.; Ruan, R. Filamentous fungi assisted bio-flocculation: A novel alternative technique for harvesting heterotrophic and autotrophic microalgal cells. Sep. Purif. Technol. 2013, 107, 158-165, https://doi.org/10.1016/j.seppur.2013.01.030.

71. Al Hattab, M.; Ghaly, A.; Hammouda, A. Microalgae Harvesting Methods for Industrial Production of Biodiesel: Critical Review and Comparative Analysis Fundamentals of Renewable Energy and Applications. J. Fundam. Rnewable Energy Appl. 2015, 5, 1-26.

72. Knuckey, R.M.; Brown, M.R.; Robert, R.; Frampton, D.M.F. Production of microalgal concentrates by flocculation and their assessment as aquaculture feeds. Aquac. Eng. 2006, 35, 300-313, https://doi.org/10.1016/j.aquaeng.2006.04.001.

73. Shah, J.H.; Deokar, A.; Patel, K.; Panchal, K.; Mehta, A.V. A Comprehensive Overview on Various Method of Harvesting Microalgae According to Indian Perspective. Int. Conf. Multidiscip. Res. Pract. 2014, 1, 313317.

74. Wang, Z.; Hou, J.; Bowden, D.; Belovich, J.M. Evaluation of an inclined gravity settler for microalgae harvesting. J. Chem. Technol. Biotechnol. 2014, 89, 714-720, https://doi.org/10.1002/jctb.4174.

75. Pragya, N.; Pandey, K.K.; Sahoo, P.K. A review on harvesting, oil extraction and biofuels production technologies from microalgae. Renew. Sustain. Energy Rev. 2013, 24, 159-171, https://doi.org/10.1016/j.rser.2013.03.034. 
76. Trovão, M.; Pereira, H.; Silva, J.; Páramo, J.; Quelhas, P.; Santos, T.; Silva, J.T.; Machado, A.; Gouveia, L.; Barreira, L.; Varela, L. Growth performance, biochemical composition and sedimentation velocity of Tetraselmis sp. CTP4 under different salinities using low-cost lab- and pilot-scale systems. Heliyon 2019, 5 , 1-6, https://doi.org/10.1016/j.heliyon.2019.e01553.

77. Gao, Z.; Peng, X.; Zhang, H.; Luan, Z.; Fan, B. Montmorillonite-Cu(II)/Fe(III) oxides magnetic material for removal of cyanobacterial Microcystis aeruginosa and its regeneration. Desalination 2009, 247, 337-345, https://doi.org/10.1016/j.desal.2008.10.006.

78. Toh, P.Y.; Yeap, S.P.; Kong, L.P.; Ng, B.W.; Chan, D.J.C.; Ahmad, A.L.; Lim, J.K. Magnetophoretic removal of microalgae from fishpond water: Feasibility of high gradient and low gradient magnetic separation. Chem. Eng. J. 2012, 211-212, 22-30, https://doi.org/10.1016/j.cej.2012.09.051.

79. Prochazkova, G.; Podolova, N.; Safarik, I.; Zachleder, V.; Branyik, T. Physicochemical approach to freshwater microalgae harvesting with magnetic particles. Colloids Surfaces B Biointerfaces 2013, 112, 213218, https://doi.org/10.1016/j.colsurfb.2013.07.053.

80. Liu, D.; Li, F.; Zhang, B. Removal of algal blooms in freshwater using magnetic polymer. Water Sci. Technol. 2009, 59, 1085-1091, https://doi.org/10.2166/wst.2009.046.

81. Xu, L.; Guo, C.; Wang, F.; Zheng, S.; Liu, C.Z. A simple and rapid harvesting method for microalgae by in situ magnetic separation. Bioresour. Technol. 2011, 102, 10047-10051, https://doi.org/10.1016/j.biortech.2011.08.021.

82. Japar, S.A.; Azis, N.M.; Sobri, M.; Haiza, N.; Yasin, M. Application of Different Techniques to Harvest Microalgae. Trans. Sci. Technol. 2017, 4, 98-108. 